\title{
O IMPACTO DA ANEMIA FALCIFORME NA VIDA DE ADOLESCENTE*
}

\author{
Márcia Helena de Souza Freire ${ }^{1}$, Rafaela Aparecida Pereira², Evelyn Juliana Ramos ${ }^{3}$, Vanilde de Fátima Andrade Matos ${ }^{4}$
} Michelle Thais Migoto ${ }^{5}$

Enfermeira. Doutora em Saúde Pública. Docente do Departamento de Enfermagem da Universidade Federal do Paraná. Curitiba, PR, Brasil.

${ }^{2}$ Enfermeira. Residente em Saúde da Família. Secretaria Municipal de Saúde de Curitiba. Curitiba, PR, Brasil.

${ }^{3}$ Enfermeira. Fundação Estatal da Atenção Especializada à Saúde. Curitiba, PR, Brasil.

${ }^{4}$ Enfermeira. Mestranda em Psicologia. Ambulatório de Hematologia Pediátrica do Hospital de Clínicas da UFPR. Curitiba, PR, Brasil.

${ }^{5}$ Enfermeira. Mestranda em Enfermagem. Universidade Federal do Paraná. Curitiba, PR, Brasil.

RESUMO: Objetivou-se identificar o impacto da anemia falciforme no cotidiano de adolescentes. Pesquisa qualiquantitativa, descritiva e exploratória com 12 adolescentes inscritos num ambulatório da cidade de Curitiba, estado do Paraná. A coleta dos dados ocorreu entre 15 de janeiro a 30 abril de 2014. Teve como referencial teórico as Representações Sociais e metodológico o Discurso do Sujeito Coletivo. Dos resultados encontrados, metade dos adolescentes era afrodescendente, quase todos foram diagnosticados na Triagem Neonatal no Teste do Pezinho. Os jovens demonstraram algum conhecimento da doença; a maioria referiu não se sentir diferente perante outros adolescentes sem a doença; foram frequentes os relatos de dor, cansaço, uso de medicamentos e limitações ao convívio social; o motivo de internação mais frequente foi por crise álgica. Ações educativas em serviços de saúde, com foco nas singularidades de paciente e família, minimizarão os impactos da doença e promoverão qualidade de vida dos jovens com anemia falciforme.

DESCRITORES: Anemia falciforme; Doença crônica; Adolescente; Enfermagem em saúde pública; Pesquisa qualitativa.

\section{THE IMPACT OF SICKLE CELL DISEASE ON THE DAILY ROUTINE OF ADOLESCENTS}

ABSTRACT: The present study aimed to identify the impact of sickle cell disease on the daily lives of adolescents. Exploratory, descriptive, qualitative and quantitative research with 12 adolescents enrolled in an outpatient unit of the city of Curitiba, state of Paraná. Data collection was performed between January 15 and April 30, 2014. The theory of Social Representations was the reference of the research, and the technique used was Collective Subject Discourse methodology. Half of the adolescents were of African descent, and almost all of them were diagnosed at the National Newborn Screening Program - Guthrie test The youngsters had some knowledge of the disease; most of them reported not feeling different from other adolescents not affected by the disease; there were frequent reports of pain, fatigue, medication use and limitations of social life; the most common reason for hospitalization was pain episodes. Educational actions in health services focused on the characteristics of the patients and their families, will minimize the impacts of the disease and promote the quality of life of adolescents with sickle cell disease.

DESCRIPTORS: Sickle cell disease; chronic disease; Adolescent; Nursing in public health; Qualitative research.

\section{EL IMPACTO DE LA ANEMIA FALCIFORME EN LA VIDA DE ADOLESCENTE}

RESUMEN: Estudio cuya finalidad fue identificar el impacto de la anemia falciforme en el cotidiano de adolescentes. Investigación cualitativa cuantitativa, descriptiva y exploratoria con 12 adolescentes inscriptos en ambulatorio de la ciudad de Curitiba, Paraná. Los datos fueron obtenidos entre 15 de enero y 30 de abril de 2014. El referencial teórico fue de las Representaciones Sociales y, el metodológico, del Discurso del Sujeto Colectivo. Acerca de los resultados, mitad de los adolescentes era afrodescendiente, casi todos fueron diagnosticados en la Selección Neonatal en el Test de Guthrie. Los jóvenes demostraron algún conocimiento de la enfermedad; la mayoría declara no sentirse diferente delante de otros adolescentes sin la enfermedad; fueron frecuentes los relatos de dolor, cansancio, uso de medicamentos y limitaciones del convivir social; el motivo de internación más frecuente fue por crisis de dolor. Acciones educativas en servicios de salud, con foco en las singularidades de paciente y familia podrán minimizar los impactos de la enfermedad y promover cualidad de vida de los jóvenes con anemia falciforme.

DESCRIPTORES: Anemia Falciforme; Enfermedad Crónica; Adolescente; Enfermería en Salud Pública; Investigación Cualitativa.

*Artigo extraído do Trabalho de Conclusão de Curso intitulado "Anemia falciforme à luz da enfermagem: caracterização dos portadores, impacto pessoal e familiar, promoção em saúde". Universidade Federal do Paraná, 2014.

\section{Autor Correspondente:}

Márcia Helena de Souza Freire

Universidade Federal do Paraná

R. José de Mello Braga Júnior, 143, 81540-280 - Curitiba, PR, Brasil

E-mail: marcia.freire@ufpr.br
Recebido: $07 / 07 / 2015$

Finalizado: 11/08/2015 


\section{INTRODUÇÃO}

A anemia falciforme (AF) é uma doença crônica, de etiologia genética, autossômica e recessiva, mediante o gene Hemoglobina $\mathrm{S}(\mathrm{HbS})$ originário das populações do continente Africano e Região Mediterrânea, com manifestação prevalente nos afrodescendentes e sua propagação relacionada à imigração dos descendentes. Portanto, é uma patologia que implica em um marcador étnico de relevância ${ }^{(1)}$, e reconhecida pela Organização Mundial da Saúde (OMS) como uma prioridade por ser considerada um problema de saúde pública devido a sua morbimortalidade em menores de 5 anos.

Estudo internacional realizado com o Banco de Dados de Migração (World Bank's Global Bilateral Migration Database) evidenciou aumento no número de pessoas com $\mathrm{HbS}$ com o fenômeno da globalização, como resultado do consequente aumento do movimento de imigração e miscigenação em países dos continentes europeu, americano e asiático. Elevação igualmente verificada nos países de origem africana ${ }^{(2)}$.

A tendência estimada do comportamento das doenças falciformes é de elevação no número global de recém-nascidos, de 305.800 em 2010, para $404.200 \mathrm{em}$ 2050. Este acréscimo tem ocorrido expressivamente na Nigéria e República Democrática do Congo, e o decréscimo na Índia. Frente ao cenário, recomenda-se a implementação de diferentes níveis de medidas de intervenção em saúde, para que vidas de crianças com doença falciforme (DF) abaixo de cinco anos de idade, possam ser poupadas ${ }^{(1)}$, em especial, as políticas para o aconselhamento genético e rastreamento das populações ${ }^{(2)}$.

As pessoas com AF apresentam sintomatologia variada, com manifestações diversas para cada indivíduo. As mais comuns como dor, palidez, febre e náusea, além de afetar diversos órgãos, ainda causam impactos de ordem emocional e social, que comprometem a qualidade de vida do indivíduo ${ }^{(3)}$ e de suas famílias, sobretudo no ciclo vital da infância e adolescência.

Em países desenvolvidos, as principais causas de complicações de crianças com AF entre 1 e 3 anos são infecções, sequestro esplênico agudo e síndrome da dor torácica. Neste sentido, reiterase que o diagnóstico precoce e o tratamento abrangente são ações que estão reduzindo a mortalidade e elevando a sobrevida de doentes crônicos $^{(4)}$, mas apresentam expectativa de vida reduzida, menor que 45 anos, com complicações na maioria dos doentes ${ }^{(5)}$.

Para a redução do impacto da $\mathrm{AF}$, devem ser priorizadas políticas governamentais para o controle da doença, mediada pela educação em saúde, desenvolvida especialmente na esfera da atenção primária à saúde e em centros especializados.

Portanto, conhecer as dificuldades e desafios enfrentados pelos indivíduos com AF pode subsidiar a capacitação de profissionais de saúde, como disseminadores do conhecimento e o manejo singular das adversidades ocasionadas pela doença. Assim, justifica-se a relevância desta pesquisa que buscou identificar o impacto da $\mathrm{AF}$ no cotidiano dos adolescentes.

\section{MÉTODOS}

Pesquisa quali-quantitativa, descritiva, realizada em um Ambulatório de Hematologia Pediátrica, na cidade de Curitiba, estado do Paraná. Trata-se de um serviço de referência estadual para o acompanhamento e tratamento de hemoglobinopatias. A coleta dos dados empíricos ocorreu no período de 15 de janeiro a 30 abril de 2014. Foi utilizado nas entrevistas um instrumento semi-estruturado, além de dados quantitativos para caracterização dos adolescentes. As variáveis desta caracterização foram: idade, etnia, sexo, escolaridade, tipo de acompanhante do adolescente, número de internações e motivos. As entrevistas contemplaram: $\mathrm{O}$ que você entende por anemia falciforme? Fale um pouco sobre quando e como foi feito seu diagnóstico? Como você se sente em relação aos seus colegas? A anemia falciforme interfere nas suas atividades? Você tem alguma sugestão para este ambulatório?

Como critério de inclusão dos participantes, relacionou-se: idade entre 12 e 25 anos e estar em sala de espera nos dias de consultas, estabelecidos para coleta de dados. Os participantes foram selecionados a partir de uma análise prévia da lista de consultas e do prontuário individual, para verificar se contemplavam os critérios de inclusão. Os termos de consentimento e de assentimento livres e esclarecidos foram assinados, respeitando o direito à desistência a qualquer momento. Foram entrevistados 12 adolescentes.

O método de análise e apresentação dos dados foram relativos à técnica do Discurso do Sujeito Coletivo (DSC) $)^{(6)}$, que permite a expressão de um coletivo mediante discursos na primeira pessoa do singular, e contempla a fala na íntegra dos respondentes, representando a 
visão ou significado coletivo. O DSC tem como fundamento teórico a Representação Social (RS), pelo melhor conhecimento da realidade social compartilhada para o favorecimento de uma maneira de intervenção sobre ela ${ }^{(7)}$.

Com o apoio do Qualiquantisoft ${ }^{\oplus}$, trabalhouse o substrato empírico coletado das respostas dos participantes. De cada resposta foram eleitas as Expressões-Chave (ECH), que traduziam a essencialidade de cada trecho da resposta. Para síntese e agrupamento das ECH partiu-se para a identificação de Ideia Central (IC) veiculada por cada ECH. A eleição de categorias de análise se deu de maneira organizada, com os pesquisadores respeitando todos os segmentos discursivos semelhantes que apontaram para semelhantes conhecimentos ou de significados. Como finalização do processo metodológico, obtiveram-se os discursos-síntese relativos à cada categoria de análise. Portanto, cada DSC foi definido mediante fragmentos discursivos de todas as respostas a cada pergunta, o número de suas aparições nas respostas é quantificado com apoio do software e expresso como força de compartilhamento ou representatividade da ideia, apresentada por número percentual ${ }^{(7)}$.

O rigor do estudo foi observado mediante a utilização dos critérios Consolidados para o Reporting da Pesquisa Qualitativa (COREQ) como ferramenta de apoio ao relato explícito e abrangente de estudos qualitativos. Contém 32 itens, no formato de um check list, e oportuniza ao pesquisador apresentar sistematicamente importantes aspectos da equipe de pesquisa, métodos e contexto de estudo, achados, a análise e suas interpretações ${ }^{(8)}$.

A pesquisa guarda-chuva que contempla este estudo, teve início após a aprovação do Projeto de pesquisa pelos Comitês de Ética em Pesquisa do Setor de Ciências da Saúde, e do Hospital ao qual pertence o referido Ambulatório, conforme o parecer $N^{\circ} 84718$ de 29 de agosto de 2012.

\section{RESULTADOS}

Foram entrevistados 12 adolescentes, com idade entre 12 a 17 anos, oito dos quais com 12 anos; predomínio de participantes do sexo feminino (10); etnia negra seis; estudantes do ensino fundamental (10); cinco procedentes da $2^{a}$ Regional de Saúde (RS) do Estado do Paraná, que tem como município sede Curitiba; acompanhados por suas mães (11); e que sofreram hospitalizações devido às crises álgicas (10), como observado na Tabela 1.
Tabela 1 - Caracterização sociodemográfica dos adolescentes com anemia falciforme, Ambulatório de Hematologia Pediátrica. Curitiba, PR, Brasil, 2014

\begin{tabular}{lcc} 
Variáveis & N & $\%$ \\
\hline Sexo & & \\
\hline Feminino & 10 & 83,3 \\
\hline Masculino & 2 & 16,7 \\
\hline Idade & & \\
\hline 12 anos & 8 & 66,7 \\
\hline 13 anos & 4 & 33,3 \\
\hline Etnia & & \\
\hline Negra & 6 & 50 \\
\hline Pardo & 3 & 25 \\
\hline Branca & 3 & 25 \\
\hline Escolaridade & & \\
\hline Ensino fundamental & 10 & 83,3 \\
\hline Ensino médio & 2 & 16,7 \\
\hline Procedência & & \\
\hline $2^{a}$ RS & 5 & 41,7 \\
\hline Outras RS & 6 & 50 \\
\hline Outro Estado & 1 & 8,3 \\
\hline Acompanhantes & & \\
\hline Mãe & 11 & 60,1 \\
\hline Outro Familiar & 7 & 39,9 \\
\hline Internações & & \\
\hline Crises de dor & 2 & 62,5 \\
\hline Outras Causas & \multicolumn{2}{c}{10,6} \\
\hline Não Internado & & \\
\hline
\end{tabular}

Os DSC síntese foram organizados em categorias, com o apoio do Qualiquantisoft ${ }^{\circledR}$, de acordo com as semelhanças das IC quantificadas nas respostas, apresentadas com frequência simples e relativa, esta última apontando força de expressão das categorias (Quadro 1).

\section{Conhecimento sobre anemia falciforme}

Os participantes relataram ter algum conhecimento sobre a anemia falciforme. As respostas foram divididas em duas categorias: desconhecimento e entendimento. Ambos com $50 \%$ de força de compartilhamento.

Desconhecimento: "Não... não sei. Quando estava na outra casa tinha umas palestras, era dividido, um lugar para as crianças e outro para os pais, daí eu ficava na das crianças. Não sei muita coisa, nunca me explicaram direito" (DSC-A).

Conhecimento: "Sei que afeta minha rede sanguínea, que é uma doença sem cura, minha mãe me falou isso... Que deforma as células do sangue, 
Quadro 1 - Distribuição das perguntas e das categorias segundo sua frequência (n) e força de expressão (\%) nos discursos individuais, Ambulatório de Hematologia Pediátrica. Curitiba, PR, Brasil, 2014

\begin{tabular}{|lcc|}
\hline Perguntas e Categorias & N & $\%$ \\
Pergunta 1: O que você entende por AF? & 6 & 50 \\
A. Desconhecimento & 6 & 50 \\
B. Conhecimento & & \\
Pergunta 2: Fale-me um pouco sobre quando e como foi feito seu diagnóstico. & 8 & 66,7 \\
A. Com a Triagem Neonatal & 4 & 33,3 \\
B. Por investigação de morbidades/internações & \\
Pergunta 3: Como você se sente em relação aos seus colegas? & 2 & 16,7 \\
A. Sente-se diferente & 10 & 83,3 \\
B. Não se sente diferente & 10 & 62,5 \\
Pergunta 4: Como a AF interfere nas suas atividades do dia-a-dia? & 3 & 18,7 \\
A. Fisicamente & 3 & 18,7 \\
B. Socialmente & 11 & 47,8 \\
C. Não interfere & 12 & 52,2 \\
Pergunta 5: Como é o tratamento que você realiza nesse ambulatório? & & \\
A. Consultas & 11 & 91,7 \\
B. Medicação & 1 & 8,3 \\
Pergunta 6: Você tem alguma sugestão para que este ambulatório lhe atenda melhor? & & \\
A. Expressa satisfação & & \\
B. Insatisfeito com a doença & & \\
\hline
\end{tabular}

sempre os médicos tão falando... células deformadas, de todo o corpo. Sei que tem o traço que junta e causa a doença. Eu sei que AF é quando a pessoa tem mais glóbulos brancos do que vermelhos. Eu aprendi aqui e na escola também" (DSC-B).

\section{Diagnóstico da doença}

Os entrevistados falaram como foram realizados seus diagnósticos, $66,7 \%$ das expressões apontaram para a Triagem Neonatal e demais mediante a investigação das morbidades.

Com a Triagem Neonatal: "Acho que logo depois que eu nasci. A minha mãe descobriu no Teste do Pezinho... com quatro meses de vida" (DSC-A).

Por investigação de morbidades/internações: "Minha mãe falou que quando eu nasci... no Teste do Pezinho não apareceu. Mas quando eu fiz três anos eu fui fazer um exame e apareceu. Eu tinha sintomas e fiquei internada com nove meses, ninguém sabia o que era. Faz três anos, eu ficava muito internada. Quando eu tinha seis anos, mas só depois que minha irmã nasceu porque deu nela e eu tive que fazer $o$ exame" (DSC-B).

\section{Como se percebem em relação aos demais adolescentes}

Quando indagados sobre como se percebem em relação a outros adolescentes que não têm $\mathrm{AF}$, a maioria dos entrevistados (83,3\%) relatou não se sentir diferente perante os colegas, enquanto o restante $(16,7 \%)$ refere se sentir diferente devido limitações da doença, como pode ser observado no discurso.

Sente-se diferente: "Às vezes eu não posso correr muito por causa da minha perna, que dói. Eles (os amigos) dizem que eu não tenho muita diferença, mas sou mais limitado. Enquanto eles continuando correndo, eu tenho que dar umas paradas... Mas, isso eu acho que é pessoal... os outros não vão notar que eu 'to' cansado. Quando eu corro demais o ar seca, aí eu começo a passar mal, é estranho. Eu me acho pequena... nessas férias todo mundo cresceu, eu fiquei do mesmo tamanho" (DSC-A).

\section{Interferência da anemia falciforme no cotidiano de vida}

Apesar de não se sentirem diferentes dos demais devido à doença, os adolescentes entrevistados reconhecem que a $\mathrm{AF}$ interfere no seu cotidiano, com maior força de expressão $(62,5 \%)$ no âmbito físico, com potencial fator limitante.

Fisicamente: "Tem dias que ela (AF) fica atacada e começo a ficar com dor. Tem vezes quando eu 'to' muito doente eu acabo ficando com muita dor de cabeça. Só para correr eu tenho dor na perna, e 
embaixo da costela. Quando eu corro não me sinto muito cansada... eu tenho um pouco de dificuldade, quando eu corro muito eu tenho falta de ar. Na educação física, eu canso às vezes, e o professor acha que é frescura minha... é que ele ainda não sabe o que tenho... como vou consultar hoje vou levar um papel falando para ele do meu problema. Às vezes eu sinto muita dor, daí com muita dor mesmo... não posso correr muito, se eu correr muito eu fico com dor no pé e me sinto meio cansada. Eu acho que foi o que eu disse mesmo: as atividades físicas" (DSC-A).

Socialmente: "Interfere um pouco, porque eu perco escola, perco de ver meus amigos e isso é chato... fico quieta no meu canto... fico deitada e minha mãe me dá remédio... eu venho no hospital internar" (DSC-B).

\section{Rotina do tratamento e consultas}

Como resposta ao tratamento que realizam no ambulatório, cenário desta pesquisa, foram analisados os discursos dos adolescentes que evidenciaram o tratamento, quais medicações faziam uso e periodicidade de suas consultas. Como discursos-síntese foram definidas duas categorias: rotina de medicações e de consultas, com força de compartilhamento de $52,2 \%$ e $47,8 \%$, respectivamente.

Consultas: "Eu venho uma vez por mês... de em cinco em cinco dias... cada dois meses... de três em três meses, ou de quatro em quatro meses, depende acho que é isso. Eu consulto e se eu estiver bem eu posso ir embora, se não tiver bem... eu fico aqui" (DSC-A).

Medicação: "Eu tomo um remédio que é pra quem tem $A F$, hidroxiureia, ácido fólico, captopril e digoxina. A hidroxiureia é especial só para a minha doença, captopril eu tomo para não aumentar minha pressão, para dor dipirona e paracetamol. Eu tenho dor às vezes, ontem eu 'tava' com dor de cabeça, tomei remédio e passou. Venho fazer transfusão, que eles (profissionais de saúde) falam que é 'pra' tirar as células com anemia" (DSC-B).

\section{Percepção do atendimento no ambulatório}

Nesse discurso os adolescentes eram questionados sobre como era ser atendido no ambulatório e quais sugestões gostariam de fazer para a melhoria do serviço. A maioria $(91,7 \%)$ expressou satisfação com o atendimento e apenas um participante demonstrou insatisfação, que estava relacionada à doença e não ao ambulatório.

Expressa satisfação: "Não, 'tá' tudo bom. Legal, eu gosto de vir e por causa da escolinha. Não tem o que melhorar" (DSC-A).

Insatisfeito com a doença: "Mais ou menos, não gosto muito, porque além de eu não gostar de acordar cedo, não gosto de pensar que tenho essa doença. Não me sinto mal por ter a doença, só não gosto de vir" (DSC-B).

\section{DISCUSSÃO}

Embora encontrada prevalência da AF no sexo feminino, não é relatada evidência de sua relação com $\operatorname{sexo}^{(9)}$. Estudo realizado em Uberaba, em 2008, identificou que $52,4 \%$ pessoas com $\mathrm{AF}$ eram do sexo feminino(5). Esta prevalência pode ter relação com o discreto predomínio de mulheres $(4,2 \%)$ na população brasileira ${ }^{(10)}$.

O fato de terem, em sua maioria, 12 anos e quase $70 \%$ dos entrevistados terem sido diagnosticados mediante a Triagem Neonatal (TN) evidencia o resultado positivo do Programa Nacional de Triagem Neonatal que ocorreu em $2001^{(11)}$ e regulamenta ações para diagnóstico precoce e tratamento da DF. No entanto, observase que quatro deles passaram por internações para serem diagnosticados, situação que pode indicar a existência de maternidades sem TN regulada. No Paraná, com a detecção da AF na TN, o recém-nascido é encaminhado para um Serviço de Referência em Triagem Neonatal, a FEPE (Centro de Pesquisas da Fundação Ecumênica de Proteção ao Excepcional) realizada a confirmação diagnóstica e encaminhamento para serviço especializado para tratamento clínico ${ }^{(12)}$.

Estudo qualitativo realizado em Pernambuco, com acompanhantes de pessoas com AF, aponta que o cuidado está centralizado na figura materna. Refere que a doença afetou toda a família propiciando dificuldades no relacionamento familiar. Afirmam que a mulher é culturalmente determinada a cumprir as obrigações de núcleo familiar, enquanto o homem cumpre atividade remunerada ${ }^{(13)}$. Destarte, mesmo inserida em outros cenários, a mulher, frente a uma doença crônica, abre mão de outros papéis para exercer seu papel de cuidadora principal.

Neste estudo, $50 \%$ dos participantes identificaram-se como negros e $25 \%$ pardos. O Paraná possui 18 municípios com 34 comunidades de remanescentes de quilombos, e 10 comunidades negras tradicionais. Foi também o primeiro estado do Brasil a incluir no pré-natal a realização do exame eletroforese de hemoglobina na rotina de exames da gestante, que detecta, em 
especial, a $\mathrm{AF}^{(14)}$. Um estudo retrospectivo, com dados secundários, em Uberaba, identificou a variável coloração da pele em apenas 7,8\% dos participantes, destes 4,9\% eram negros e 1,9\% eram pardos ${ }^{(5)}$. Ressalta-se que o importante componente étnico da AF justifica o rigor do registro desta informação.

Uma das preocupações dos pesquisadores foi identificar o que os adolescentes sabiam de sua doença, e a metade dos entrevistados expressou algum entendimento, mesmo que parcial ou insuficiente. $O$ fato de a outra metade relatar desconhecimento foi preocupante, pois para prevenção dos agravos é necessário que o adolescente com AF entenda sobre a doença para estar competente para o autocuidado e comprometido com o tratamento. Uma análise dos óbitos de pacientes com AF em Minas Gerais apontou que $40 \%$ deles ocorreram por volta de 24 horas do início dos sintomas. Com o conhecimento do período de maior risco de agravamento do quadro e óbito, os autores apontaram a formação continuada para a equipe de saúde, e a educação em saúde para os familiares, como essenciais para detecção e prevenção das complicações e óbito ${ }^{(15)}$.

Dos adolescentes entrevistados, a maioria $(83,3 \%)$ relatou não se sentir diferente pelo fato de ter $\mathrm{AF}$, identidade esta devida ao fato de ser uma doença crônica genética, com a qual toda a família convive desde o nascimento. É possível identificar no DSC que a doença Ihes traz situações de conflito relacionadas à dor e limitações, e se sentem diferentes pelas limitações da própria doença e pelo crescimento físico deficiente. Este último relacionado à sobrecarga de ferro devido às recorrentes transfusões, que potencialmente podem gerar distúrbios endócrinos e retardo no crescimento ${ }^{(16)}$.

Crises dolorosas podem ter duração de 2 horas ou mais, ocasionalmente em braços, pernas, costas, abdômen, tórax e cabeça, fortemente associadas à má qualidade de vida ${ }^{(17)}$ e são as que mais levam às internações ${ }^{(17,9)}$. Os sintomas identificados pelos familiares no início do adoecimento foram febre, dor, palidez e vômito, sendo que a crise álgica reincidente em quase $60 \%$ das crianças $^{(15)}$. Essa realidade afeta a autoestima e a socialização, pois a hospitalização promove a separação dos familiares e amigos ${ }^{(18)}$. O uso contínuo de hidroxiureia é importante, pois favorece o aumento da hemoglobina para o combate da anemia hemolítica, no entanto, o único tratamento curativo é o transplante de células-tronco ${ }^{(19)}$. Nesta ótica, ressalta-se que existe uma fragilidade na identificação de complicações da AF pelos profissionais e familiares ${ }^{(15)}$, desfavorecendo o tratamento em tempo oportuno.

Entende-se que as medidas preventivas são necessárias para controle da dor e o tratamento de infecções, com elevação da expectativa e da qualidade de vida. Assim, a frequência ao serviço de referência para as consultas e monitoramento causa impacto sobre o convívio social e escolarização. Conhecer as experiências dos portadores de AF permite a organização e priorização do cuidado de enfermagem, além de ações que auxiliem o equilíbrio integral da família. Incentivar autocuidado é importante na adaptação e significa zelo com o corpo, favorecendo a autoobservação dos sinais do corpo ${ }^{(20)}$.

Os adolescentes expressaram satisfação com o serviço ambulatorial, refletindo provavelmente na qualidade de vida depois de iniciar o tratamento. A satisfação do usuário favorece a acessibilidade, a formação de vínculo e a abertura para a atuação da equipe multidisciplinar na assistência a $\mathrm{AF}^{(13)}$.

Os participantes que expressaram insatisfação relacionaram-na com a doença, discurso esperado por doentes crônicos, pois é desafiador e gera sentimentos contraditórios no processo de aceitação da doença ao buscar entendêla e conviver com suas diversas ordens de limitações. Neste sentido, valoriza-se o suporte psicoterapêutico no favorecimento de amplo conhecimento da realidade vivenciada pelos pacientes $^{(21)}$ e estratégias de enfrentamento.

\section{CONSIDERAÇÕES FINAIS}

O desenvolvimento desta pesquisa, com um número limitado de participantes e restrita ao universo de serviço de referência, aponta a representação da doença crônica e seu impacto na vida destes. Seus resultados poderão auxiliar no estabelecimento de possibilidades e prioridades para uma assistência integral ao doente falciforme.

Recomenda-se (re)pensar as ações de educação em saúde nos serviços de saúde, com foco nas singularidades de cada família e paciente adolescente, para que se tenha sucesso na minimização dos impactos da doença crônica e na promoção da qualidade de vida. No caso, a adolescência contempla questionamentos que necessitam de especificidades de informações, apoio e esclarecimentos, face às falas dos adolescentes sobre o impacto da AF em seu crescimento, desenvolvimento e socialização. 
Há necessidade de mais serviços de referência para hemoglobinopatas no estado do Paraná, tendo em vista que quase metade dos usuários do ambulatório, cenário desta pesquisa, era procedente de outros municípios. Os deslocamentos frequentes geram impacto negativo na escolarização e provavelmente na empregabilidade de seus responsáveis.

Aos profissionais envolvidos na assistência aos adolescentes com AF, sugere-se capacitação continuada em seus ambientes de trabalho. Para melhor compreensão do impacto da $\mathrm{AF}$ contribuiriam outras pesquisas em cenários e com populações diversas, como familiares, profissionais de saúde e gestores dos serviços especializados.

\section{REFERÊNCIAS}

1. Piel FB, Hay SI, Gupta S, Weatherall DJ, Williams TN. Global burden of sickle cell anaemia in children under five, 2010-2050: Modelling based on demographics, excess mortality, and interventions. PLOS Med. [Internet] 2013;10(7) [acesso em 07 jul 2015]. Disponível: 10.1371/journal.pmed.1001484.

2. Piel FB, Tatem AJ, Huang Z, Gupta S, Williams TN, Weatherall DJ. Global migration and the changing distribution of sickle hemoglobin: a quantitative study of temporal trends between 1960 and 2000. Lancetgt. [Internet] 2014; 2. [acesso em 07 jul 2015]. Disponível: http://dx.doi.org/10.1016/S2214-109X(13)70150-5.

3. Santos JP, Gomes Neto M. Sociodemographic aspects and quality of life of patients with sickle cell anemia. Rev. Bras. Hematol. Hemoter. [Internet] 2013; 35(4). [acesso em 07 jul 2015]. Disponível: http://dx.doi. org/10.5581/1516-8484.20130093.

4. Ansong D, Akoto AO, Ocloo D, Ohene-Frempong K. Sickle cell disease: Management options and challenges in developing countries. Mediterr J Hematol Infect Dis. [Internet] 2013; 5(1). [acesso em 07 jul 2015]. Disponível: doi:10.4084/MJHID.2013.062.

5. Martins PRJ, Souza HM, Silveira TB. Morbiditymortality in sickle cell disease. Rev. Bras. Hematol. Hemoter. [Internet] 2010; 32(5). [acesso em 07 jul 2015]. Disponível: http://dx.doi.org/10.1590/S151684842010000500010 .

6. Lefèvre F, Lefèvre AMC. The Collective Subject that speaks. Interface. 2006; 10(20):517-24.

7. Jodelet D. Ponto de vista: sobre o movimento das representações sociais na comunidade científica brasileira. Temas Psicol. 2011, vol.19, n.1, pp. 19-26. ISSN 1413-389X.

8. Tong A, Sainsbury P, Graig J. Consolidated criteria for reposrting qualitative research (COREQ): a 32-item check list for interviews and focus group. Inter.Journ. Qual. Health Care. [Internet] 2007; 19(6). [acesso em 07 jul 2015]. Disponível: DOI: http://dx.doi.org/10.1093/ intqhc/mzm042.

9. Santos PND, Freire MHS, Zanlorenzi GB, Pianovski MA, Denardi VFAM. Anemia falciforme: caracterização dos pacientes atendidos em um ambulatório de referência. Cogitare Enferm. [Internet] 2014; 19(4). Disponível: http://dx.doi.org/10.5380/ce.v19i4.36657.

10. Instituto Brasileiro de Geografia e Estatística (IBGE). Censo demográfico e contagem da população 2010. [Internet] [acesso em 07 jul 2015]. Disponível: http:// censo2010.ibge.gov.br/resultados.

11. Brasil. Ministério da Saúde. Secretaria de Atenção à Saúde. Departamento de Atenção Especializada. Doença falciforme: condutas básicas para o tratamento. Brasília: Ministério da Saúde, 2012. [acesso em 07 jul 2015]. Disponível: http://bvsms.saude.gov.br/bvs/ publicacoes/doenca_falciforme_condutas_basicas. pdf.

12. Federação Espírita do Paraná. Teste do Pezinho, 2014. [Internet] [acesso em 07 jul 2015]. Disponível: http://www.fepe.org.br/triagem.html.

13. Guimarães TMR, Miranda WL, Tavares MMF. The day-to-day life of families with children and adolescents with sickle cell anemia. Rev. Bras. Hematol. Hemoter. [Internet] 2009; 31(1). [acesso em 07 jul 2015]. Disponível: http://dx.doi.org/10.1590/S151684842009005000002 .

14. Secretaria Estadual de Saúde do Paraná. Boletim Informativo Semanal - e-Saúde. Paraná [Internet] 2014 [acesso em 07 jul 2015] Disponível: http:// www.sesa.pr.gov.br/modules/conteudo/conteudo. php? conteudo $=2867$

15. Sabarense AP, Lima GO, Silva LML, Viana MB. Characterization of mortality in children with sickle cell disease diagnosed through the Newborn Screening Program. J Pediatr. [Internet] 2015; 91. [acesso em 07 jul 2015]. Disponível: doi:10.1016/j.jped.2014.08.006.

16. Felix AA, Souza HM, Ribeiro SBF. Epidemiologic and social aspects of sickle cell disease. Rev. Bras. Hematol. Hemoter. [Internet] 2010; 32(3). [acesso em 07 jul 2015]. Disponível: doi:10.1016/j.jped.2014.08.006.

17. Makani J, Ofori-Acquah SF, Nnodu O, Wonkam A, Ohene-Frempong K. Sickle cell disease: new opportunities and challenges in Africa. The Scientific World Journal. [Internet] 2013, 193252. [acesso em 07 jul 2015]. Disponível: http://dx.doi. org/10.1155/2013/193252.

18. Dias TL, Oliveira CGT, Enumo SRF, Paula KMP. Pain the daily life of caregivers and children with sickle 
cell anemia. Psicol. USP.[Internet] 2013; 24(3). [acesso em 07 jul 2015]. Disponível: http://dx.doi.org/10.1590/ S0103-65642013000300003

19. Editorial. Boosting services for people with sicklecell disease. [Internet] 2010; 376. [Acesso em 07 jul 2015]. Disponível: DOI: http://dx.doi.org/10.1016/ S0140-6736(13)60030-6.

20. Cordeiro RC, Ferreira SL, Santos ACC. Experiências do adoecimento de pessoas com anemia falciforme e estratégias de autocuidado. Acta paul. enferm. [Internet] 2014;27(6). [acesso em 07 jul 2015]. Disponível: http://dx.doi.org/10.1590/1982-0194201400082.

21. Savassi LCM. Patient Satisfaction and Self-perceived Health in Primary Care. R. Bras. Med. Fam. e Comum. [Internet].2010; 5(17). [acesso em 7 jul 2015]. Disponível: DOI: http://dx.doi.org/10.5712/rbmfc5(17)135. 